\title{
Enhancing information literacy through the application of whole brain strategies
}

\author{
Ann-Louise de Boer*, Theo Bothma** and Pieter H du Toit***
}

Department of Information Science and Department of Humanities Education, University of Pretoria, Pretoria, South Africa

*ann-louise.deboer@up.ac.za **theo.bothma@up.ac.za *** pieter.dutoit@up.ac.za

Abstract

This article reports a research project in which the thinking preferences of a group of students enrolled for a module on information literacy at the University of Pretoria were determined. Annually about 7000 first-year students enrol for this module. The main aim of the research project was to determine to what extent the traditional approach to offering the module could be changed with a view to accommodating students with differing thinking preferences and enhancing the quality of learning. To get a holistic perspective on learning the theory on whole brain learning and the application of Herrmann's whole brain learning inventory were applied and investigated.

The research forms part of an overarching interdisciplinary research project that focuses on facilitating whole brain information literacy. Since the focus is on investigating a specific practice, action research is used as scholarly process for professional development. The action research approach includes mixed methods. This mix allows for merging quantitative and qualitative studies.

The first phase of the project consisted of a baseline study. It entailed a quantitative approach to determining the students' learning style profiles by means of the Herrmann Brain Dominance Instrument (HBDI) - used as a diagnostic assessment tool. The outcome of this diagnostic assessment forms part of the baseline data for the envisaged longitudinal study.

Introduction

All first-year students enrolling at the University of Pretoria have to be computer literate. The credit-bearing semester module in information literacy offered by the Department of Information Science forms part of the University's drive to promote literacy skills of which information literacy is an integral part. As implied in the vision of the University (University of Pretoria 2006), students are to become leaders in their respective fields of specialisation at an international level. This necessitates becoming independent, developing leadership skills and contributing to the development of South Africa as part of the innovation generation and leading minds - two slogans recently and currently used in promotional material of the University. Qualities such as independence, leadership and scholarly thinking feature in policy documents on higher education and education in general as they are inter alia to be found in the critical cross-field outcomes as discussed in Smith (2006) overarching outcomes that are applicable to all learning programmes. The module is a 
fundamental module for all degree programmes offered at the University. About 7000 first year students enrol for the module annually.

Navigating Information Literacy (Bothma, Cosijn, Fourie and Penzhorn 2008) is an information society survival toolkit that is used as core learning material. It captures a range of skills and topics essential for students who intend positioning themselves in academic or workplace environments that are globally connected and competitive.

The content of the textbook is structured as follows: Chapter 1 addresses the what, why and how of information literacy. Chapter 2 focuses on information sources and resources, giving an overview of what resources are available and how to find information. The functional differences between portals, gateways and library websites form the core of chapter 3 while chapter 4 offers guidelines on how to construct a search query using the Internet. Chapter 5 highlights searching the Internet and chapter 6 addresses database searches and online journals. Skills on how to retrieve and organise information on a computer are focused on in chapter 7 and in chapter 8 attention is given to the ethical aspects of using information and issues such as plagiarism and copyright infringement. Chapter 9 deals with correct referencing and referencing techniques one uses with a focus on the Harvard method. Students are normally confronted with an overload of information and therefore chapter 10 outlines evaluating information and information sources. Chapter 11 deals with writing assignments and research reports and chapter 12 is included to make students aware of the various $21^{\text {st }}$ century communication systems.

As scholars of teaching and learning in higher education we as authors are constantly aware of being knowledgeable about our practice, as Ramsden $(1999,3)$ reminds us: "If you really want to improve your own teaching, you must understand what that something is." We appreciate the complexity of that practice as an interrelated mix of different aspects. It could not be oversimplified as a setting where a learner, a teacher, and learning material form the main components as indicated by Renzulli and Dai (2001) for the school context. The same is applicable to the context of higher education.

The rationale for the study is the imperative all higher education practitioners have, namely to improve their practices in an innovative and accountable way. This is for instance promoted in policy documents of the Council on Higher Education (CHE) (2003) and would imply choosing a sound theoretical basis for application in our practice. An applicable and accountable research design should complement our professional development as well as that of all staff involved.

The theoretical basis for this study is whole brain learning (Herrmann 1995). This study supports Andrew, Pheiffer, Green and Holley's (2002) idea of applying the principles of learning styles beyond the matching hypothesis. The matching hypothesis in essence would mean that teaching styles have to accommodate learners' learning styles. Instead a developmental approach is proposed. The idea of developing the full potential of learners is promoted. Therefore Kolb's idea "that we should rather begin to stretch learning capacities in other learning modes" (Ibid, 6) becomes evident. This most important turning point in learning style theories is also highlighted in the so-called Coffield report (Coffield, Moseley, Hall and Ecclestone 2004).

Any higher education practitioner has an array of related roles to fulfil as stipulated in recent literature, specifically the Norms and Standards for Educators (South Africa 1999). The role of curriculum designer and interpreter, facilitator of learning, assessor, researcher and lifelong learner and their interrelatedness form the core of the sub-project discussed in this paper.

For the purpose of investigating the entire information literacy programme an interdisciplinary research project has been initiated. It is a very large and integrated 
longitudinal study that involves numerous internal stakeholders from within the university community and external stakeholders. Only one section of the first phase of the overarching study is reported in this article. It comprises a baseline study that offers a set of quantitative data that will be used as baseline data for all sub-projects - setting the scene for all related research endeavours in future.

\section{Research question}

The research project referred to above has as focus the following overarching question: How can the principles of whole brain learning be used to enhance the quality of the information literacy module offered at the University of Pretoria?

This research question is refined by means of an array of sub-questions that are aligned with the respective sub-projects. The following question that forms part of the baseline study indicates the unit of analysis that is reported here: What are the learning styles of the first year students enrolling for the information literacy module at the University of Pretoria?

To be able to address this question, an appropriate research method or methods should be deployed. Such research methods form part of an overarching research design. The research design for the overarching project is discussed next.

\section{Research design}

The interdisciplinary research study referred to above falls under the pragmatic paradigm (Green and Caracelli 2003). An action research study (Zuber-Skerritt 2000) forms the research design. It consists of a mix of research methods as proposed by Tashakkori and Teddlie (2003). Our intention eith the research is twofold. We mainly focus on our professional development and the professional development of all lecturers involved, but at the same time we investigate the possibilities of using the principles of action research to innovate the information literacy module. We therefore need a dynamic process-driven design that can easily be adapted as needs arise. Taking a combined pragmatic-dialectic position (Rocco, Bliss, Gallagher, Perez-Prado, Alacaci, Dwyer, Fine and Pappamihiel 2003 ) is therefore regarded as accountable in our specific context.

Characteristics of case study research (Yin 2004) and evaluation research (Mouton 2001) are also used. For the purpose of gathering data, Blaxter, Hughes and Tight's (2002) view of combining quantitative and qualitative data is taken. Mouton's (2001) description of this design type is applied as follows: Implementation evaluation research aims to answer the question whether an intervention has been properly implemented, and whether the target group has been adequately covered. The case study under investigation comprises a large group of nearly 7000 students enrolled for the module under investigation and small groups of up to 13 part-time lecturers (annually changing) that teach the module. Our intention was to establish the module as an exemplar of whole brain learning (Herrmann 1995) and learning-centredness (Du Toit 2008). Individual preferences are respected. At the same time we aim at developing the full potential of learners and lecturers alike. This is done by challenging them to work in modes that would expect them to execute tasks calling on capacities beyond their comfort zones. For the lecturers it would be to design learning and assessment opportunities that would not fit their preferred way of doing. For example, a lecturer who is used to presenting lectures in a one-way communication mode 
is challenged to plan for group work that would promote participative learning and group assignments. Students who prefer to read on their own would be challenged to co-operate with others.

This specific part of the empirical study reported here was done in the following way: Characteristics of the group of learners' preferred learning styles were identified by means of the HBDI (Herrmann 1995). Determining the learners' learning style preferences helps us in assessing the current practice from the viewpoint of learners' perceived needs. The outcome of the $\mathrm{HBDI}$ is used to inform the practice insofar the curriculum design, facilitating of learning and the assessment practice are concerned.

The investigation implies analysing a unit of analysis with a view to establishing generalisations (Cohen and Manion 2000). In our case the unit of analysis is learning style preferences. Deductions made at the end of the study are not a generalisation to higher education as such, but of the underpinning theory under investigation (Yin 2004).

Action research has been selected as an appropriate research design. Action research is defined as a "Collaborative, critical enquiry by the academics themselves ... into their practice, into problems of students' learning and into curriculum problems" (Zuber-Skerritt $1992,1)$. The principles of action research as opportunity-driven, a change intervention and opportunity for improvement (Blaxter, Hughes and Tight 2002) are applicable. However, working in the context of education innovation and experimenting with innovative ideas, we opted for an asset-based approach as proposed by Du Toit (2008). Instead of asking "What is wrong with my practice?" (aligned with the traditional way of identifying a research problem) or asking "What is my concern?" (McNiff 2008) we identify an innovative idea to experiment with and to investigate. The innovative idea here is applying the principles of whole brain learning to all aspects of designing and developing a curriculum for information literacy which inter alia includes curriculum development, facilitating learning, assessment, learning and professional development of academic staff and all researchers involved.

Most action research scholars refer to problem identification (Zuber-Skerritt 2000; Burton and Bartlett 2005) or identifying a concern (McNiff and Whitehead 2006) as one of the phases of an action research project or as a point of departure. Identifying a problem and formulating a so-called research problem is typical of traditional research and to us a deficit-based approach to action research. Instead we propose focusing on our own assets, our students' and lecturers' involved or identifying a new idea. This would change action research into an asset-based approach (Du Toit 2008). Especially within a visionary model one would rather work with innovative ideas in curriculum development, facilitating learning and assessment that one would like to try out in one's higher education practice. Working within and asset-based approech is more about experimenting with new ideas (see quadrant $D$ in the Herrmann model referred to further on) than solving existing problems. Our own learning style preferences as practitioner researchers and students should be seen as an asset that can be explored and developed to the full. In terms of learning style flexibility there might be other latent potential to be discovered and developed. Potential means growth and implies assets students or lecturers may have. Another asset all humans have is the fact that we all have multiple intelligences at our disposal (Gardner 1993)

For the purpose of triangulation (as proposed by Blaxter, Hughes and Tight 2002) multiple data sources and methods are used. These reveal the complexity and uniqueness of the beliefs, experiences and values of the participants. Our beliefs, experiences and values regarding learning are constructed as a learning theory that serves as theoretical framework for this article. 
Two propositions are implied in the research questions stated earlier on, the first being that the principles of WBL be applied in the module under investigation for the purpose of innovation. The second is that the implementation of WBL be scientifically monitored by means of action research. These propositions have given impetus to the constructing of our learning theory. Therefore one needs to focus on the essence of the following:

- $\quad$ Learning style preferences

- $\quad$ Action research as a learning process in higher education

The essence of our constructed learning theory is subsequently outlined.

Theoretical framework

As higher education practitioners we are aware of the fact that the information literacy practice is multidimensional and complex. Any theoretical framework should reflect this complexity. However, for the purpose of this article, we focus on the theory of whole brain learning (also referred to as learning style flexibility) with the following aspects in mind:

- $\quad$ Education system: Principles of outcomes-based education

- Principles of accountable curriculum development: Critical cross-field outcomes, learning outcomes, study manual

- $\quad$ Methods of facilitating learning

- $\quad$ Assessment practice: Diagnostic, formative and summative assessment

- $\quad$ Adult learning theories: Learning styles, self-regulated learning, co-operative learning, deep learning, action learning, multiple intelligences

- $\quad$ Education innovation

- $\quad$ Educational change and transformation

The Coffield research report (Coffield 2004), an independent report commissioned through the University of London by the Learning Skills Council in England was published in 2004. The report documents an investigation into the wide range of existing learning style instruments designed to identify a learner's preferred style of learning.

The report evaluates the main theories about learning styles and selects the most important models from the literature. This was done by means of assessing the theoretical robustness of each model and evaluating the implications of these models for learning.

The Coffield report (2004) concludes that Herrmann's whole brain model and instrument (HBDI) is one of six recommended models in education and training. The Herrmann model not only identifies a preference of thinking within a specific mode but also a low preference for a thinking mode. This is perhaps the most significant for learning success because one of the keys to excellence in facilitating learning is to find appropriate learning strategies to address those low preferences, some of which may be essential to success in a particular field of specialisation. 
Literature overview of Herrmann's model ${ }^{\circledR}$

\section{Earlier Brain Research}

Earlier brain research by MacLean and Sperry, as reported by De Boer, Steyn and Du Toit (2001), indicated the left hemisphere as being the logical, analytical, quantitative and rational hemisphere, whereas the right hemisphere deals with conceptual, holistic, intuitive, imaginative and non-verbal aspects. MacLean's research showed that the cerebral system, the limbic system and the brain stem do different kinds of thinking. Sperry and his co-workers won a Nobel Prize in 1981 for their work on left and right hemispheres of the brain that illustrates those different hemispheres do different thinking tasks - even when they do the same task they go about it differently. In this regard De Boer et al (2001) cite the following important phrase: "We do not see things as they are; we see things as we are".

\section{The Herrmann Whole Brain Model}

In the early 1980s Ned Herrmann proposed a model to explain how the brain physiologically works: how it thinks, learns, creates, solves problems, communicates, etc. Herrmann $(1995 ; 1996)$. He combined the research of Sperry regarding the left-right brain and the cerebral-limbic modes of MacLean into a whole-brain model ${ }^{\circ}$. Herrmann's model shows the left and right of reason (cerebral system), and the left and right of emotion (limbic system). These four quadrants are the thinking areas of the brain - because they have neural cortices (areas shown to be involved in thinking). Each quarter has very distinct clusters of cognitive functions.

The concept Whole Brain $®$ Teaching and Learning is based on human's distribution of specialised modes throughout the brain system as depicted in the figure below.

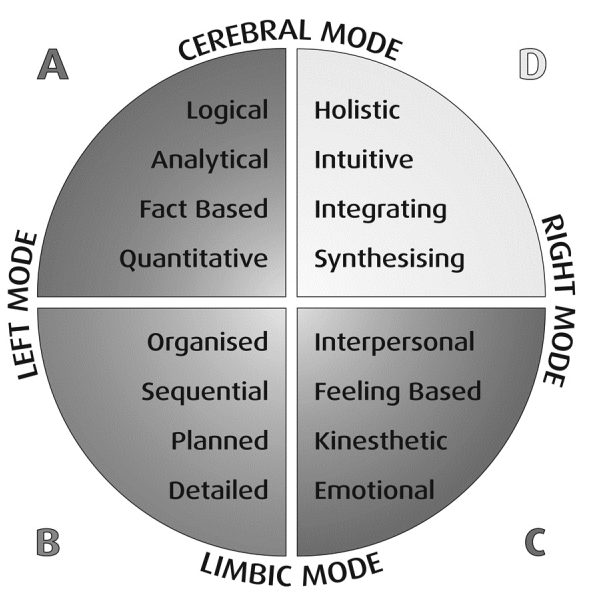

Figure 1: Whole Brain Learning Model (Herrmann 1995; 1996) 
Herrmann's widely published work describes the model as a metaphoric four quadrant model (1995; 1996). These specialised mental modes function together situationally and interactively, making up a whole brain, in which one or more parts become naturally dominant. The Herrmann Brain Dominance Instrument $\mathrm{HBDI}^{\mathrm{TM}}$ is a validated assessment tool that quantifies the degree of a person's preference for specific thinking modes.

Herrmann (1995) states that a preference for the A quadrant (left cerebral mode) means that a person favours activities that involve logic, analytical and fact-based information. Such a person may have a low preference for vague, imprecise concepts or ideas, a lack of logic and expressing emotions. A preference for the B quadrant (processes of the left limbic mode) implies a linear approach to activities. Individuals with a B quadrant preference favour organised, sequential, planned and detailed information with a low preference for taking risks, unclear concepts and instructions, and ambiguity. A preference for the $C$ quadrant (processes of the right limbic mode) indicates favouring information that is interpersonal, feeling-based and involves emotion. People with this mode of thinking have a low preference for too much data and analysis, a lack of interaction and a lack of time for relationships. A preference for the $D$ quadrant (processes of the right cerebral mode) is mainly characterised by a holistic and conceptual approach to thinking with a low preference for overtly strict time management, lack of flexibility and too much detail. He concludes that there is an equal distribution of learners across the four quadrants.

Although an individual may favour cognitive activities associated with a specific quadrant, both left and right hemispheres contribute to how we learn, but they contribute differently. Each quadrant is different, but equal in importance. Fortunately we are not linked to a single perspective - but we are in fact "hard wired to be whole" (Herrmann 1995).

The assessment tool ( $\mathrm{HBDI}^{\mathrm{TM}}$ ) is based on 30 years of extensive research on brain dominance with over 2 million learners in the database worldwide. It proves that the whole is more than the sum of the parts and therefore using different design and delivery approaches improves the learning experiences of learners.

\section{Discussion and implication for teaching and learning}

Herrmann (1995) writes that our knowledge of the brain and its inherent uniqueness clearly indicates that each individual is a unique learner with learning experiences, preferences and avoidances that will be different from those of other learners. This means that the design of learning opportunities must somehow acknowledge the uniqueness of the individual learner. An immediate implication for the education and training profession is that assumptions about learning should take into account that our unique learning similarities and differences become part of the learning design and experience and should be made visible. As a result, learning is no longer one dimensional but includes the notion of multiple intelligences as Howard Gardner's (1996) work demonstrates. This implies that all the learners can master the subject - not just those that are in alignment with the design of learning programmes and the teaching/training style or mode.

Using different design and delivery approaches improves and facilitates the learning experience by engaging learners in each of these four specialised quadrants; providing learners different options. Planning for this flexible way of learning must be done thoughtfully so that one does not overwhelm learners by providing a deluge of modalities that might overflow them. This approach creates a design that moves back and forth with techniques and activities from each of the four quadrants because it is also a known fact 
that the brain is capable of zigzagging around the four quadrant model when learning; however, each critical learning point needs to be paraphrased in each mode at some point in the learning process.

With Herrmann's whole brain $\odot$ model as a diagnostic tool, it is possible to design the leaning programme to meet that unique requirement.

In most instances lecturers will not have access to information on their learners' profiles, or at best will be able to guess only. Therefore the most successful approach is to design learning opportunities to create a whole brain experience for a whole brain leaning group.

\section{Research Findings}

The sample of 1004 students was subdivided into the various disciplines the students represented. We extracted the following five disciplines from our database to show that the different student groups - in different faculties and different fields of specialisation - to a very large extent conformed to the composite group profile: IT students $(n=132)$, medical students $(n=103)$, engineering students $(n=210)$, psychology students $(n=71)$, students enrolled for drama and music $(n=55)$.

Figure 2 represents the composite group profile of the overall project (1004 students). It displays a composite whole and is in accordance with research findings pertaining to Herrmann's model. "People are distributed throughout the teaching and learning model in terms of their mental preferences and the profiles represent a highly diverse, but a wellbalanced distribution across the four quadrants of the whole brain" Herrmann $(1996,47)$.

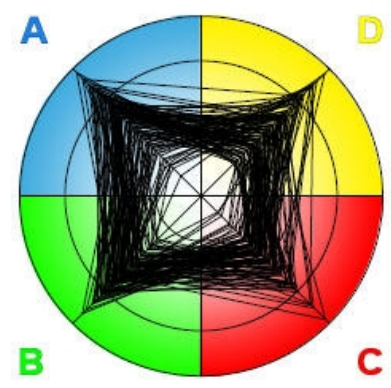

Figure 2: Composite group profile

The group profile depicted in the figure above consists of a compilation of groups of students from five different fields of specialisation - each with its own group profile. These group profiles are represented below. It should be kept in mind that the larger the group sample, the more whole brained the group profile will be. This is clear when the group of engineering students $(n=220)$ is for example compared to the smaller group of drama/music students $(n=55)$. 
IT $(n=132)$

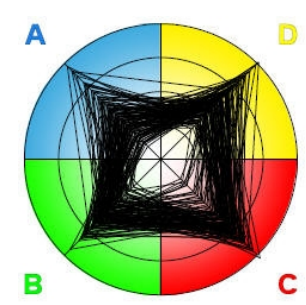

Psychology $(n=71)$ Drama/Music $(n=55)$
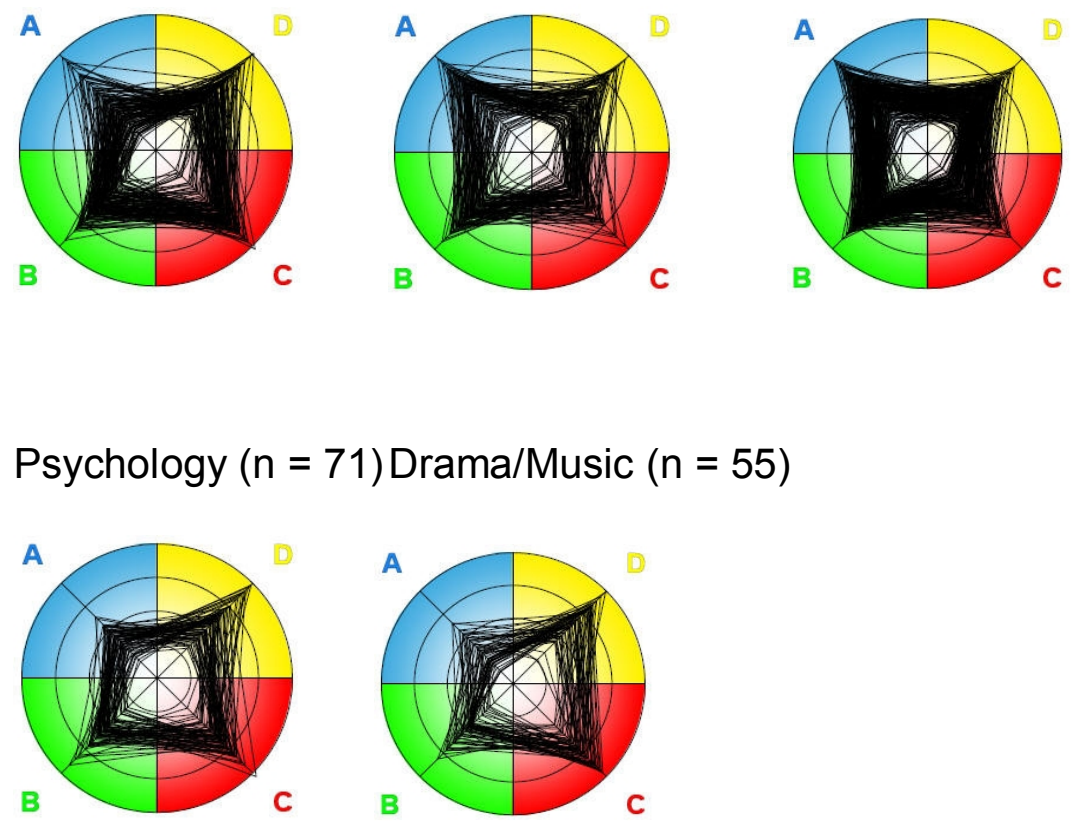

Figure 3: Composite group profiles of five groups of specialisation

If we superimpose the five individual groups in figure 3 , the composite profile indicates preferred modes of thinking in all four quadrants (figure 2). This implies that methods of facilitating learning need to be adapted to make provision for different thinking styles across all disciplines.

An application of Herrmann's model in terms of facilitating learning necessitates that lecturers become aware of their own thinking preferences and the implications thereof for their teaching practices. The following serve as examples in this regard:

- $\quad$ For the strong A quadrant lecturer facilitating learning could include using data and challenging problems to solve, having rigorous debates with question-and-answersessions. Such a lecturer might also expect students to present citations and might like to involve specialists in the applicable field of specialisation.

- $\quad$ For the B quadrant lecturer learning opportunities could include well-structured activities, detailed programme material with clear instructions of where to find the information or how to execute a task. Practical concrete examples and ample time to practise and review what learners have learned are offered.

- $\quad$ For the $C$ quadrant lecturer team work or team projects focusing much on hands-on activities could be typical learning opportunities. Interpersonal activities such as small group discussions and sharing personal reactions with interesting human stories are situations in which lecturers feel at ease and might use that as basis for creating learning opportunities.

- $\quad$ For the $\mathrm{D}$ quadrant lecturer learning opportunities could include discovering activities using visuals and metaphors. Brain storming sessions on futuristic topics and constantly being aware of the big picture overview are activities that will be included in learning opportunities. 
From the preceding facts and data it is clear that the current teaching approach in information literacy of "one size fits all" does not optimise learning for all. The methods of facilitating learning should make provision for differentiation of learning materials to accommodate different learning style preferences. Therefore, in addition to making provision for differentiation of learning materials, learning content, learning outcomes, learning and assessment opportunities should also be differentiated to make provision for different learning style preferences. Furthermore, learners' less preferred learning style preferences should be challenged in order to develop their full potential - by executing tasks that expect learners to go beyond their comfort zone or preferred style of learning. With this in mind the current information literacy curriculum is being revised and forms part of this extended project.

The results of the HBDI have profound implications for the development of a curriculum for information literacy, viz.:

- To develop and accommodate A quadrant thinking one should design learning opportunities that include formal lectures, facts, research findings, reasoning, critical thinking, textbook readings and case studies, use of experts, logic, data and theories.

- $\quad$ Learning opportunities that would develop and accommodate B quadrant thinking should include clear agendas and outlines, study manuals, checklists, worksheets, policies and procedures, summaries, step-by-step exercises and problems that need solving by means of a sequential, step-by-step approach.

- To develop and accommodate C quadrant thinking one should incorporate cooperative learning experiences, group discussions, role play, mime and drama, body language, sharing of personal experiences, listening to ideas, story telling and interviews as part of the learning.

- $\quad$ Developing and accommodating $\mathrm{D}$ quadrant thinking can be obtained by means of learning opportunities that incorporate mind mapping, putting ideas into new models, synthesising, brainstorming of concepts, drawing of mental pictures, such as mind maps and being creative.

Learning opportunities that provide for implementing all the modes of Herrmann's model will ensure that learners' preferred thinking modes are accommodated and less preferred thinking modes are utilised as well.

\section{Conclusion}

The baseline data of the project, pertaining to the students' profiles, reveal a diversity of thinking style preferences across the various fields of specialisation and are therefore in accordance with the notion that "every classroom represents a complete spectrum of learning style preferences" (Herrmann 1996, 151).

We also acknowledge the fact that most individuals are not singular in their preferences and that everyone has access to all four modes. Yet, each individual is a unique learner with learning experiences, preferences and avoidances that will be different from those of 
other learners. Therefore the design of learning opportunities in information literacy should somehow acknowledge the uniqueness of the individual learner.

Lecturers have become aware of the fact that for any group of learners there is a composite array of learning style preferences as well as learning avoidances (nonpreferred mode of thinking) across the four quadrants and that "learning avoidances are even more significant than learning preferences because they turn people off - a turnedoff learner is a waste of educational time and effort" (Herrmann 1996, 152). De Boer et al (2001) cite the following important fact that is being adapted to the context of this study: If professors teach exclusively in a manner that favours their students' less preferred learning style modes, the students' discomfort level may be great enough to interfere with their learning. On the other hand, if professors teach exclusively in their students' preferred modes, the students may not develop the mental dexterity they need to reach their potential for achievement at university and as professionals.

It is imperative for every lecturer, including those responsible for teaching information literacy, to be aware of his/her own thinking style preferences and their implication for his/her teaching style in order to develop the full potential of learners and their own full potential as lecturer. Adopting a whole brain approach to facilitating learning will develop a learner's full potential and should form the basis of all education practices.

With the aim of promoting education innovation it is imperative that lecturers appreciate the fact that the world is a whole brain place - as represented by any classroom. Lecturers should plan for the various challenges that accommodating learners with different learning styles brings by designing whole brained multi-modal learning opportunities for the applicable learning programme. In the end it is about balance according to the nature of the field of specialisation. Indeed the balance will differ in accounting opposed to psychology, because of the differing nature of these fields of specialisation. In this way the design will benefit each learner in terms of what he/she needs while challenging him/her at the same time into other, less preferred but available modes.

Whole brain $®$ design and delivery approaches help learners with different learning preferences and interests to learn effectively and to develop into flexible learners. Whether one is designing a single learning point, module, workshop or entire learning programme, one should look out for ways to speak to the learners in all styles they may bring to the classroom.

The value of the Whole Brain ModelC developed by Herrmann (1995) and the HBDI lies in its diagnostic attributes. The model clearly indicates that any learner should be developed as a whole. Using the model and profiles (if available) as a diagnostic tool enables one to be more accountable in designing a learning programme and to plan complementary learning and assessment opportunities with a view to meeting the unique requirements of learners.

Based on the data and literature reported lecturers should reflect on the curriculum for information literacy in a diagnostic way to ensure that the curriculum, facilitating of learning and the assessment target each large group of students.

\section{Acknowledgements}

The authors would like to thank and express their gratitude to: 
Ned Herrmann and Ann Herrmann-Nehdi of Herrmann International for sponsoring the HBDI research projects at the University of Pretoria

The first-year students for taking part in the project.

\section{References}

Andrew, D, G. Pheiffer, M. Green \& D. Holley. 2002. The uses of learning styles: Beyond the matching hypothesis. Paper presented at the $7^{\text {th }}$ Annual ELSIN Conference: Learning Styles: Reliability and Validity, 26-28 June, University of Ghent, Belgium.

Bothma, T, E. Cosijn, I. Fourie \& C. Penzhorn. 2008. Navigating Information Literacy: Your Information Society Survival Tool Kit. $\left(2^{\text {nd }}\right.$ ed.) Cape Town: Pearson.

Bunderson, C.V. 1995. The validity of the Herrmann Brain Dominance Instrument. In Herrmann, N (Ed) The Creative Brain. ( $2^{\text {nd }}$ ed.) USA: Qubecor Printing Book Group.

Buzan, T. 1991. Use Both Sides of Your Brain. ( $3^{\text {rd }}$ ed.) USA: Plume Books.

Cohen, L. \& L. Manion. 2000. Research Methods in Education. $5^{\text {th }}$ Edition. London: Routledge.

Coffield, F., D. Moseley, E. Hall, \& K. Ecchelstone. 2004. Learning Styles and Pedagogy in Post-16 Learning: A Systematic and Critical Review. London: Learning and Skills Research Centre.

Council on Higher Education (CHE), South Africa. 2003. ImprovingTeaching and Learning Resource. Discussion document, Pretoria: CHE.

De Boer, A. \& T. Steyn. 1999. Thinking style preferences of underprepared first year students in the natural sciences. South African Journal of Ethnology 22 (3):97-102.

De Boer, A., T. Steyn \& P.H. Du Toit. 2001. A whole brain approach to teaching and learning in higher education. South African Journal for Higher Education 15(3): 185193.

Blaxter, L., C. Hughes, \& M. Tight. 2002. How to Research. (2 ${ }^{\text {nd }}$ ed.) Buckingham: Open University Press.

Du Toit, P.H. 2008. Matching learning style flexibility and action research for academic staff development. AERA Conference, 24-28 May, New York.

Gazzaniga, R. 1998. The split brain revisited. Scientific American 278 (1):35-39.

Gardner, H. 1993. Multiple Intelligences: The Theory in Practice. New York: Basic Books.

Greene, J. C.,\& V.J. Caracelli. 2003. Making paradigmatic sense of mixed methods practice. In A. Tashakkori, \& C. Teddlie (Eds.), Handbook of Mixed Methods in Social and Behavioral Research. Thousand Oaks: SAGE Publications.

Herrmann, N. (Ed.). 1995. The Creative Brain. ( $2^{\text {nd }}$ ed.) USA: Qubecor Printing Book Group.

Jensen, E. 1996. Brain-based Learning. Del Mar: Turning Point Publishing. 
Lumsdaine, M. \& E.E. Lumsdaine. 1995. Creative Problem Solving - Thinking Skills for a Changing World. Singapore: McGraw-Hill.

McNiff, J. 2002. Action Research for Professional Development: Concise Advice for New Action Researchers. [Online]. Available at: www.jeanmcniff.com/booklet1.html\#12 [viewed June 2, 2009].

McNiff, J. \& J. Whitehead. 2006. All You Need to Know about Action Research. London: Sage Publications.

Mouton, J. 2001. How to Succeed in Your Master's and Doctoral Studies. Pretoria: Van Schaik.

Ramsden, P. 1999. Learning to Teach in Higher Education. London: Routledge.

Renzulli, J.S. \& D.Y. Dai. Abilities, interests, and styles as aptitudes for learning: A person-situation interaction perspective. In Sternberg, R.J. \& L. Zhang (Eds).

Perspectives on Thinking, Learning, and Cognitive Styles. London: Lawrence Erlbaum Associates.

Rocco, T.S., L.A. Bliss, S. Gallagher, A. Perez-Prado, C. Alacaci, E.S. Dwyer, J.C. Fine \& N.E. Pappamihiel. 2003. The pragmatic and dialectical lenses: Two views of mixed methods use in education. In Tashakkori, A. \& C. Teddlie (Eds.). Handbook of Mixed Methods in Social and Behavioral Research. Thousand Oaks: SAGE Publications.

Shelnut, J.W, S. Middleton, K. Buch \& M. Lumsdaine. 1996. Forming student project teams based on Herrmann Brain Dominance results. American Society of Engineering Education (ASEE) Annual conference Washington DC.

Smith, D.J. 2006. Concept Analysis of Critical Cross-field Outcomes in the Context of Private Service Providers within Further Education and Training (FET). Unpublished PhD study, University of Pretoria.

South Africa. 1999. Norms and Standards for Educators. Pretoria: Government Printer.

Trigwell, K., M. Prosser \& F. Waterhouse. 1999. Relations between teachers' approaches to teaching and students' approaches to learning. Higher Education 37 (1): 57-70.

Tashakkori, A., \& C. Teddlie. (Eds.) 2003. Handbook of Mixed Methods in Social and Behavioral Research. Thousand Oaks: SAGE Publications.

University of Pretoria. 2006. Vision statement. [Online]. Available at: https://www.up.ac.za [viewed February 10, 2010].

YIN, R.K. (Ed.) 2004. The Case Study anthology. Thousand Oaks: SAGE Publications.

Zuber-Skerritt, O. 1992. Action Research in Higher Education: Examples and Reflections. London: Kogan Page.

Zuber-Skerritt, O. 2000. A generic model for action learning and research programs within organizations. Action Learning and Action Research Journal 5 (1); 41-50. 